\title{
Pilot Study on Low Penetrance Breast and Colorectal Cancer Predisposition Markers in Latvia
}

\author{
Arvids Irmejs', Edvins Miklasevics', Viktors Boroschenko', Andris Gardovskis', Andrejs Vanags', Inga Melbarde-Gorkusa', \\ Marianna Bitina', Janina Suchy², Janis Gardovskis' \\ IHereditary Cancer Institute, Riga Stradins University, Riga, Latvia; 2International Hereditary Cancer Center, Pomeranian Medical University, Szczecin, Poland
}

Key words: cancer, breast and colorectal, predisposition, markers.

Corresponding author: Arvids Irmejs, Hereditary Cancer Institute, Riga Stradins University, Dzirciema street 16, LV 1007, Riga, Latvia, phone: +3717069973, fax: +3717069973, email: hci@stradini.lv

Submitted: 1 December 2005

Accepted: 10 January 2006

\begin{abstract}
Introduction: It has not been established whether CHEK2 and NOD2 variants are present in Latvia and whether inherited variation in these genes influences cancer risk in this population.

Aim of the study: To evaluate the role of CHEK2 and NOD2 mutations in breast and colorectal cancers in the population of Latvia.

Materials and methods: Peripheral venous blood samples were collected from 185 breast cancer and 235 colorectal cancer consecutive hospital-based cases from 11/2003 to 06/2005. The population control group included blood samples from the clamped distal part of the umbilical cord from 978 consecutive anonymous newborns born between 03/2005 and 08/2005. All cases and controls were tested for the presence of NOD2 3020ins C mutation and CHEK2 1157 T mutation.

Results: NOD2 3020insC was present in 7.7\% (18/235) of CRC cancers, in 9.2\% (17/185) of breast cancers and in $7.7 \%$ (75/974) of controls. CHEK2 1157 T variant was found in $7.6 \%(14 / 185)$ of breast cancer cases, $10.2 \%(24 / 235)$ of colon cancer cases and in $6.4 \%$ (63/978) of population controls. NOD2 3020insC variant was associated with increased risk of breast cancer $(O R=2.5, p<0.05)$ for cases diagnosed at age between 51 and 60 years. CHEK2 1157T variant was associated with increased risk of colorectal cancer (OR=1.7, $\mathrm{p}<0.05$ ) with the highest $O R=2.0$ for cases diagnosed at age $>70$ yrs.

Conclusions: NOD2 3020insC and CHEK2 I157T variants may be associated with increased risk of colorectal and breast cancers in Latvia.
\end{abstract}

\section{Introduction}

There is continuing interest in identifying DNA variants which are associated with an increased risk of cancer. Several studies have suggested an increased risk of cancer in individuals who carry a mutation in the CHEK2 gene, one of the genes in the DNA damage signalling pathway. Originally, a single founder allele in CHEK2, 1100 delC, was reported to be a lowpenetrance breast cancer susceptibility allele in several studies, and in many ethnic groups [1-4]. Then, a positive association was found between CHEK2 variants and prostate cancer in the USA, Finland and Poland [5-7]. Recently, it was reported that individuals with a 
Table 1. Distribution of breast cancer and CRC group according to age at time of cancer diagnosis

\begin{tabular}{ccccc}
\hline Decade & Breast cancer & $\%$ & CRC & $\%$ \\
\hline $20-29$ & 1 & $0.60 \%$ & 2 & $0.90 \%$ \\
\hline $30-39$ & 9 & $4.90 \%$ & 4 & $1.70 \%$ \\
\hline $40-49$ & 31 & $16.90 \%$ & 14 & $6.00 \%$ \\
\hline subtotal $(<50)$ & 41 & $22.40 \%$ & 20 & $8.60 \%$ \\
\hline $50-59$ & 46 & $25.10 \%$ & 37 & $75.70 \%$ \\
\hline $60-69$ & 55 & $30.00 \%$ & 80 & $33.60 \%$ \\
\hline $70-79$ & 30 & $16.40 \%$ & 17 & $34.00 \%$ \\
\hline $80-89$ & 10 & $5.50 \%$ & 2 & $0.85 \%$ \\
\hline$>90$ & 1 & $0.55 \%$ & 215 & $91.40 \%$ \\
\hline subtotal $(>50)$ & 142 & $77.60 \%$ & 235 & \\
\hline total & $183^{*}$ & & $20 \%$ & \\
\hline
\end{tabular}

*In 2 cases time of breast cancer onset was unknown

single common founder allele in Poland (the 1157T missense variant) have increased risk of cancer development in many organs including the breast, prostate, thyroid, kidney and colon [8].

The NOD2 gene is associated with susceptibility to inflammatory bowel disease - Crohn's disease [9]. It was reported that a single truncating mutation in NOD2, 3020insC, may confer increased risk of late onset colorectal cancer [10] and then that a NOD2 mutation may be associated with increased susceptibility to lung, ovarian, early-onset laryngeal cancer and early onset breast cancer [1 1].

It has not been established whether CHEK2 and NOD2 variants are present in Latvia and whether inherited variation in these genes influences cancer risk in this population. To address these issues, we report here the results of the CHEK2 and NOD2 analyses for 185 breast cancer cases and 235 colorectal cancer cases.

\section{Methods}

From $11 / 2003$ to $06 / 2005$ family cancer history and peripheral venous blood samples were collected in 185 consecutive hospital-based breast cancer cases and 235 colorectal cancer cases. The population control group included umbilical cord blood samples from 978 consecutively collected anonymous newborn children between 03/2005 and 08/2005. Cases were considered consecutive if at least $70 \%$ of newly diagnosed patients were involved in the study from a particular hospital and department in a given period of time. In the breast cancer group, 82 cases were involved from the Regional Oncology Hospital of Daugarpils, 72 cases from the Regional Oncology Hospital of Liepaja and 31 cases from Paula Stradins University Hospital.

In the CRC group, 92 cases were involved from the Oncology Center of Latvia, 73 cases from Paula Stradins University Hospital, 46 cases from the Regional Oncology Hospital of Liepaja and 24 cases from the Regional Oncology Hospital of Daugavpils. In the CRC group 114/235 (49\%) were females and 121/235 $(51 \%)$ were males. The distribution of breast and colorectal cancers according to the age of diagnosis are summarized in Table 1.

Median age of CRC onset was 66 years and median onset of breast cancer was 60 years.

In order to evaluate the representativity of breast cancer and CRC groups, they were compared to all newly diagnosed breast and colorectal cancers diagnosed between years 1999 and 2003 in Latvia and it was concluded that breast and CRC groups are comparable to the total group of newly diagnosed breast cancers and CRCs as far as age at time of diagnosis and gender are concerned.

All cancer and control group samples were tested for the presence of NOD2 3020insC and CHEK2 1157 T polymorphisms as described by $\mathrm{G}$. Kurzawski and C. Cybulski respectively [7-10].

The study was approved by the Ethics Committee of the Pauls Stradins University Hospital and the Central Committee of Medical Ethics. 
Table 2. Prevalence of NOD2 3020insC mutation in breast cancer patients, according to age at onset

\begin{tabular}{cc}
\hline Age groups & Prevalence of NOD2 3020insC \\
\hline$<41$ & $0 \%(0 / 10)$ \\
\hline $41-50$ & $9.7 \%(3 / 31)$ \\
\hline $51-60$ & $17 \%(8 / 46)^{*}$ \\
\hline $61-70$ & $7.3 \%(4 / 55)$ \\
\hline$>70$ & $4.9 \%(2 / 41)$ \\
\hline total & $9.1 \%(17 / 185)$ \\
\hline $\begin{array}{l}\text { (7. statistically significant difference as compared to population controls } \\
\text { (75/974); OR }=2.5, p<0.05)\end{array}$
\end{tabular}

Table 3. Prevalence of CHEK2 I157T mutation in colorectal cancer cases according to age at onset

\begin{tabular}{cc}
\hline Age groups & Prevalence of CHEK2 I157T \\
\hline$<51$ & $15 \%(3 / 20)$ \\
\hline $51-60$ & $5.4 \%(2 / 37)$ \\
\hline $61-70$ & $8.9 \%(7 / 79)$ \\
\hline$>70$ & $12.1 \%(12 / 99)$ \\
\hline total & $10.2 \%(24 / 235)^{*}$ \\
\hline
\end{tabular}

* - significant difference compared to controls (6.4\% (63/978); $O R=1.7, p<0.05$ )

All patients completed a family cancer history questionnaire. Family cancer histories were analysed according to internationally approved clinical diagnostic hereditary cancer criteria. If there were no malignancies among relatives of the proband the patient was classified as being negative for a family history of the disease.

The prevalence of the CHEK2 and NOD2 alleles in cases and population controls was compared. Odds ratios were generated from two-by-two tables and statistical significance was assessed using the Fisher exact test. The odds ratios were used as estimates of relative risk.

\section{Results}

The NOD2 3020insC mutation was present in $7.7 \%(18 / 235)$ of CRC cancers, in 9.2\% (17/185) of breast cancer patients and in $7.7 \%(75 / 974)$ of the control group. The CHEK2 $1157 \mathrm{~T}$ polymorphism was found in $7.6 \%$ (14/185) of breast cancer patients, $10.2 \%(24 / 235)$ of colon cancer cases and in $6.4 \%$
(63/978) of the control group.

Statistically significant differences compared to population controls were observed: for NOD2 3020 ins $C$ for the subgroup of breast cancer patients diagnosed at the age between 51 and $60(O R=2.5$, $\mathrm{p}<0.05$ ) (Table 2); for CHEK2 I157T for the entire series of consecutive colorectal cancers $(O R=1.7, p<0.05)$. The highest odds ratio $(O R=2.0, p=0.06)$ was observed for CRC diagnosed at age $>70$ yrs (Table 3).

In seven NOD2 3020insC positive cases family cancer history was negative. In another 10 cases there were two other relatives affected with cancer in their families, which did not match any recognised diagnostic criteria of hereditary cancer. A single NOD2 3020insC positive patient had a family history of three CRCs in their family.

The average age of cancer onset for breast cancer patients harbouring NOD2 3020insC was 58 years. In six NOD2 3020insC positive breast cancer patients their family cancer history was negative. In 5/17 (29\%) cases at least two breast cancers were identified in these families and one family matched the criteria of belonging to unspecified strong cancer family aggregation (CFA).

The average age of disease onset for CHEK2 I157T positive CRC cases was 67. In 16 cases with the 11571 mutation family cancer history was negative. Among another 8 CHEK2 I157T positive CRC patients, 3/24 (13\%) matched criteria of CFA, 1/24 (4\%) case was suspected of hereditary non-polyposis colorectal cancer (HNPCC) and 1/24 (4\%) case had late-onset HNPCC.

The average age of breast cancer onset for CHEK2 1157 T positive cases was 59 years. In four CHEK2 $1157 \mathrm{~T}$ positive breast cancer cases family cancer history was negative. 8/14 (57\%) cases had familial breast cancer.

\section{Discussion and conclusions}

This first study of low penetrant CRC and breast cancer predisposition markers in Latvia shows a trend that both NOD2 3020insC and CHEK2 I157T polymorphisms are associated with increased risk of colorectal and breast cancers.

Statistically significant differences between cases and controls were not as well expressed as it has been recognised in earlier studies from Poland, probably because of the much smaller number of cases and controls, but the general trend was the same - NOD2 3020ins C was more frequent among early onset breast cancers and late onset CRCs; CHEK2 1157T was in excess among colorectal cancer and late onset breast cancer cases. In our study we focused on breast and 
colon cancers. Since for both sites we saw a similar trend as described earlier by the Polish group, we expect that the spectrum of tumours associated with mutations in NOD2 and CHEK2 in Latvia will also include other cancers. However, further studies on larger series of cancers and of different sites are necessary in this regard.

\section{References}

1. CHEK2 Breast Cancer Consortium. Low-penetrance susceptibility to breast cancer due to $\mathrm{CHEK} 2 * 1100 \mathrm{del} C$ in noncarriers of BRCA1 or BRCA2 mutations. Nat Genet 2002; 31: 55-59.

2. Oldenburg RA, Kroeze-Jansema K, Kraan J, Morreau H, Klijn JG, Hoogerbrugge N, Ligtenberg MJ, van Asperen CJ, Vasen HF, Meijers C, Meijers-Heiiboer H, de Bock TH, Cornelisse CJ and Devilee P. The CHEK2*1 100delC variant acts as a breast cancer risk modifier in non-BRCA1/BRCA2 multiple-case families. Cancer Res 2003; 63: 8153-8157.

3. Vahteristo P, Bartkova J, Eerola H, Syrjakoski K, Ojala S, Kilpivaara $\mathrm{O}$, Tamminen A, Kononen J, Aittomaki K, Heikkila P, Holli K, Blomqvist C, Bartek J, Kallioniemi OP and Nevanlinna $\mathrm{H}$. A CHEK2 genetic variant contributing to a substantial fraction of familial breast cancer. Am J Hum Genet 2002; 71: 432-438.

4. CHEK2 Breast Cancer Case-Control consortium. CHEK2*1100delC and susceptibility to breast cancer: a collaborative analysis involving 10,860 breast cancer cases and 9,065 controls from 10 studies. Am J Hum Genet 2004; 74: $1175-1182$.

5. Dong X, Wang L, Taniguchi K, Wang X, Cunningham JM, McDonnell SK, Qian C, Marks AF, Slager SL, Peterson BJ, Smith DI, Cheville JC, Blute ML, Jacobsen SJ, Schaid DJ, Tindall DJ, Thibodeau SN and Liu W. Mutations in CHEK2 associated with prostate cancer risk. Am J Hum Genet 2003; 72: 270-280.

6. Seppala EH, Ikonen T, Mononen N, Autio V, Rokman A, Matikainen MP, Tammela TL and Schleutker J. CHEK2 variants associate with hereditary prostate cancer. Br J Cancer 2003; 89: 1966-1970.

7. Cybulski C, Huzarski T, Gorski B, Masojc B, Mierzejewski M, Debniak T, Gliniewicz B, Matyjasik J, Zlowocka E, Kurzawski G, Sikorski A, Posmyk M, Szwiec M, Czajka R, Narod SA and Lubinski J. A novel founder CHEK2 mutation is associated with increased prostate cancer risk. Cancer Res 2004; 64: 2677 2679.

8. Cybulski C, Gorski B, Huzarski T, Masojc B, Mierzejewski M, Debniak T, Teodorczyk U, Byrski T, Gronwald J, Matyjasik J, Zlowocka E, Lenner M, Grabowska E, Nej K, Castaneda J, Medrek K, Szymanska A, Szymanska J, Kurzawski G, Suchy J, Oszurek O, Witek A, Narod SA and Lubinski J. CHEK2 is a multiorgan cancer susceptibility gene. Am J Hum Genet 2004; 75: 1131-1135.

9. Ogura Y, Bonen DK, Inohara N, Nicolae DL, Chen FF, Ramos $\mathrm{R}$, Britton H, Moran T, Karaliuskas R, Duerr RH, Achkar JP, Brant SR, Bayless TM, Kirschner BS, Hanauer SB, Nunez G and Cho $\mathrm{JH}$. A frameshift mutation in NOD2 associated with susceptibility to Crohn's disease. Nature 2001; 411: 603-606.

10. Kurzawski G, Suchy J, Kladny J, Grabowska E, Mierzejewski M, Jakubowska A, Debniak T, Cybulski C, Kowalska E, Szych Z, Domagala W, Scott RJ and Lubinski J. The NOD2 3020insC mutation and the risk of colorectal cancer. Cancer Res 2004; 64: 1604-1606.
11. Lubinski J, Huzarski T, Kurzawski G, Suchy J, Masoic B, Mierzejewski M, Lener M, Domagala W, Chosia M, Teodorczyk U, Medrek K, Debniak T, Złowocka E, Gronwald J, Byrski T, Grabowska E, Nej K, Szymanska A, Szymanska J, Matyjasik J, Cybulski C, Jakubowska A, Gorski B and Narod SA. The 3020insC Allele of NOD2 Predisposes to Cancers of Multiple Organs. Her Can in Clin Pract 2005; 3: 59-63. 